\title{
Serum vitamin D concentrations are non-linearly related to breast cancer risk in postmenopausal women
}

\author{
Layan Sukik, Bushra Hoque, Linda Boutefnouchet \\ Supervised by: Professor Vijay Ganji \\ Human Nutrition Department, College of Health Sciences, Qatar University, QU Health, Doha, Qatar
}

\section{Introduction}

Serum D [25(OH)D] is commonly used as a biomarker of vitamin D status. Recently, the role of vitamin $D$ in non-calcemic functions has received much attention. In the US, the prevalence of low serum $25(\mathrm{OH}) \mathrm{D}[<50 \mathrm{nmol} / \mathrm{l}]$ among postmenopausal women was $53 \%$. Cancer is the second leading cause of death worldwide. Several studies have linked vitamin $D$ deficiency with cancer. It is not known if suboptimal vitamin $\mathrm{D}$ concentrations are related to cancer risk in postmenopausal women.

\section{Objective}

The aim of this study was to investigate the association between serum 25(OH)D concentration and breast cancer risk in postmenopausal women in the US

\section{Methodology}

- Standardized serum 25(OH)D concentrations were used.

- Breast cancer was self-reported by participants.

- Serum 25(OH)D was stratified into 5 categories based on recommendations of Institute of Medicine and Endocrine Society. Multivariate-adjusted logistic regression analysis was performed to determine association between serum 25(OH)D and breast cancer after adjusting data for confounding variables (below).

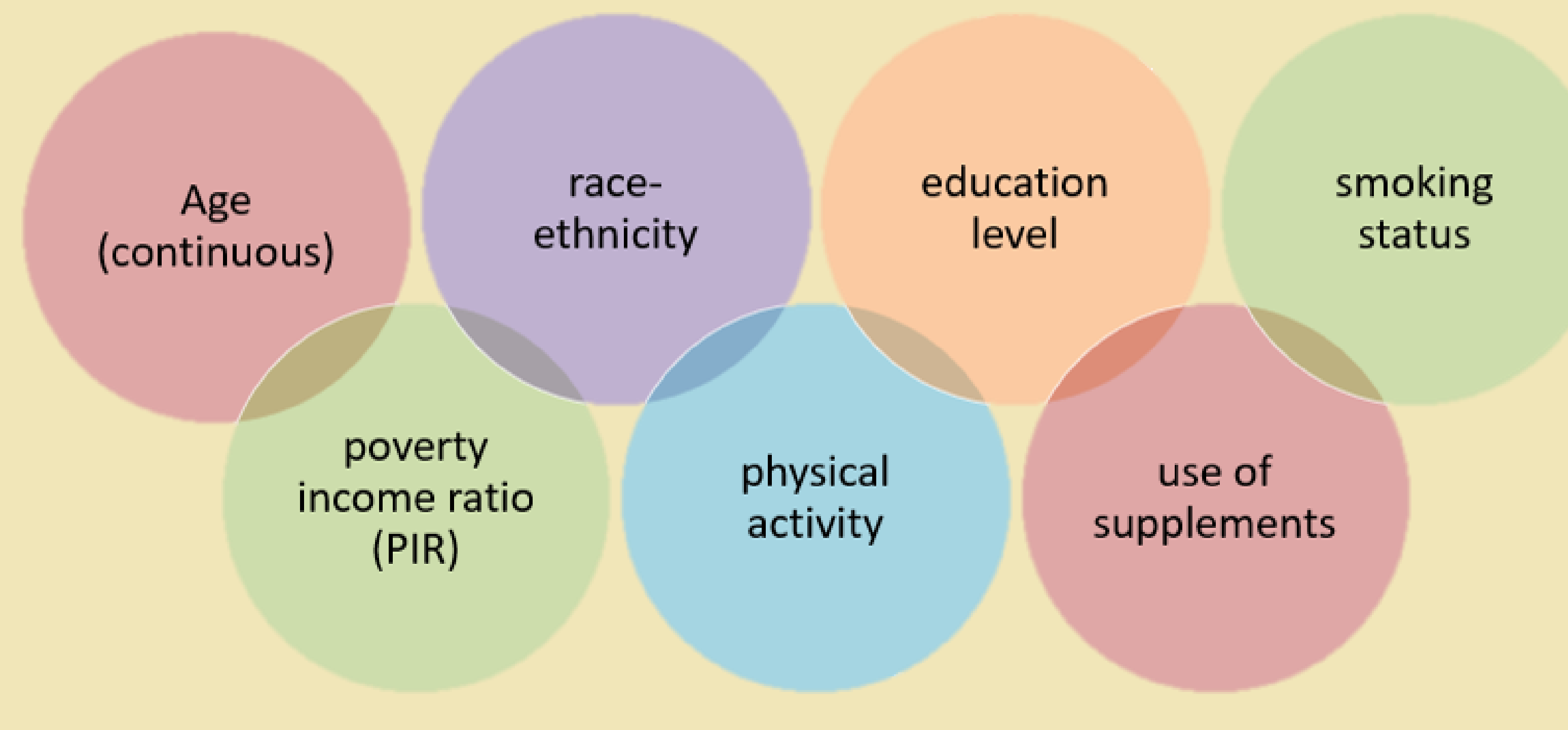

- Subgroup analyses for various races were also performed. Restrict cubic spline method with three knots at 5th, 50th and 95th were used to analyze the non-linear trend. Statistical significance: $p<0.05$.

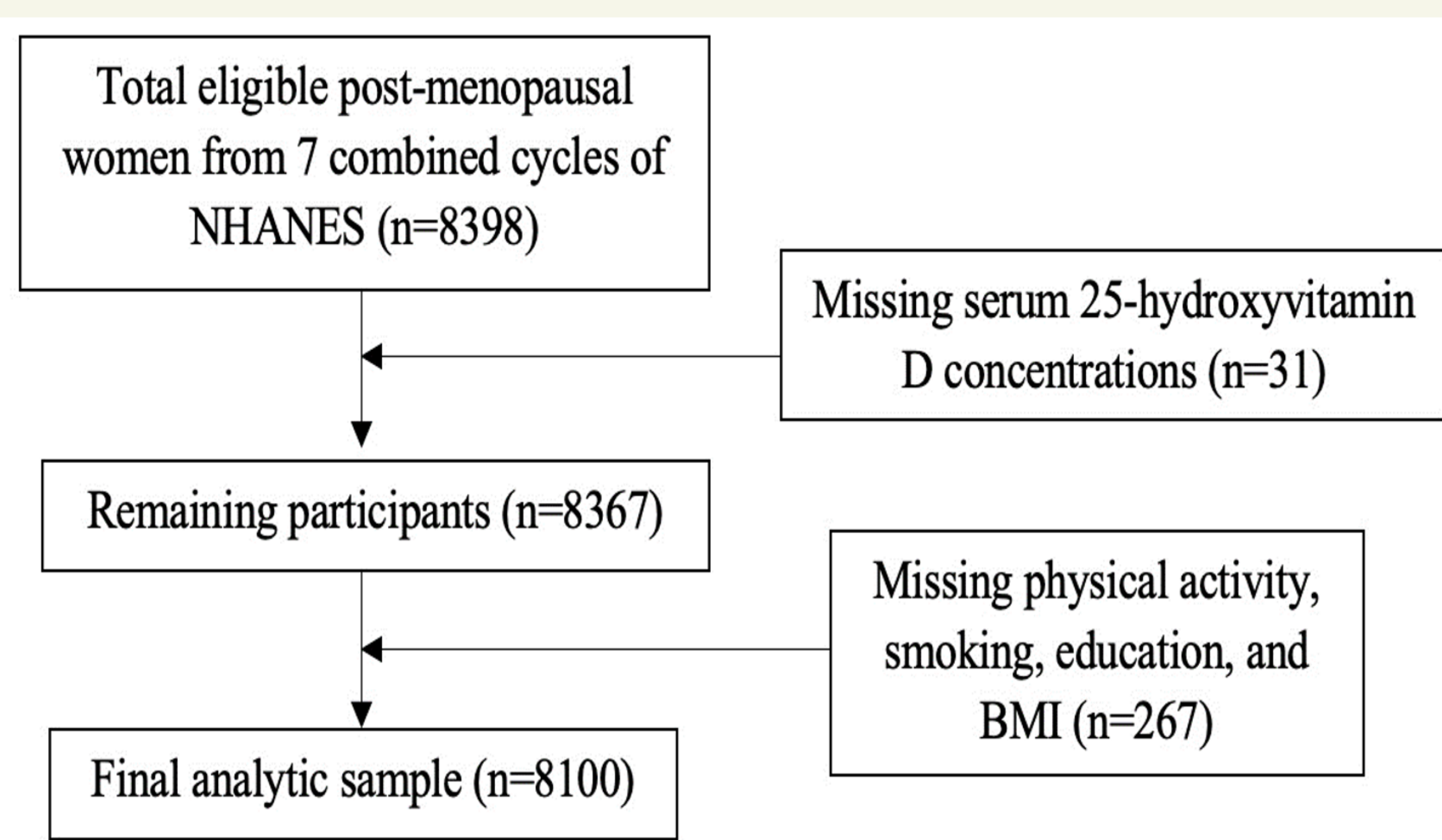

Figure 1: Sample derivation, National Health and Nutrition Examination Survey 2001-2014.

\section{Results}

Age, race, education, smoking, alcohol intake, season of the survey, BMI, supplement intake, HRT, physical activity, and PIR were significantly related to serum $25(\mathrm{OH}) \mathrm{D}(\mathrm{P}<0.001)$.

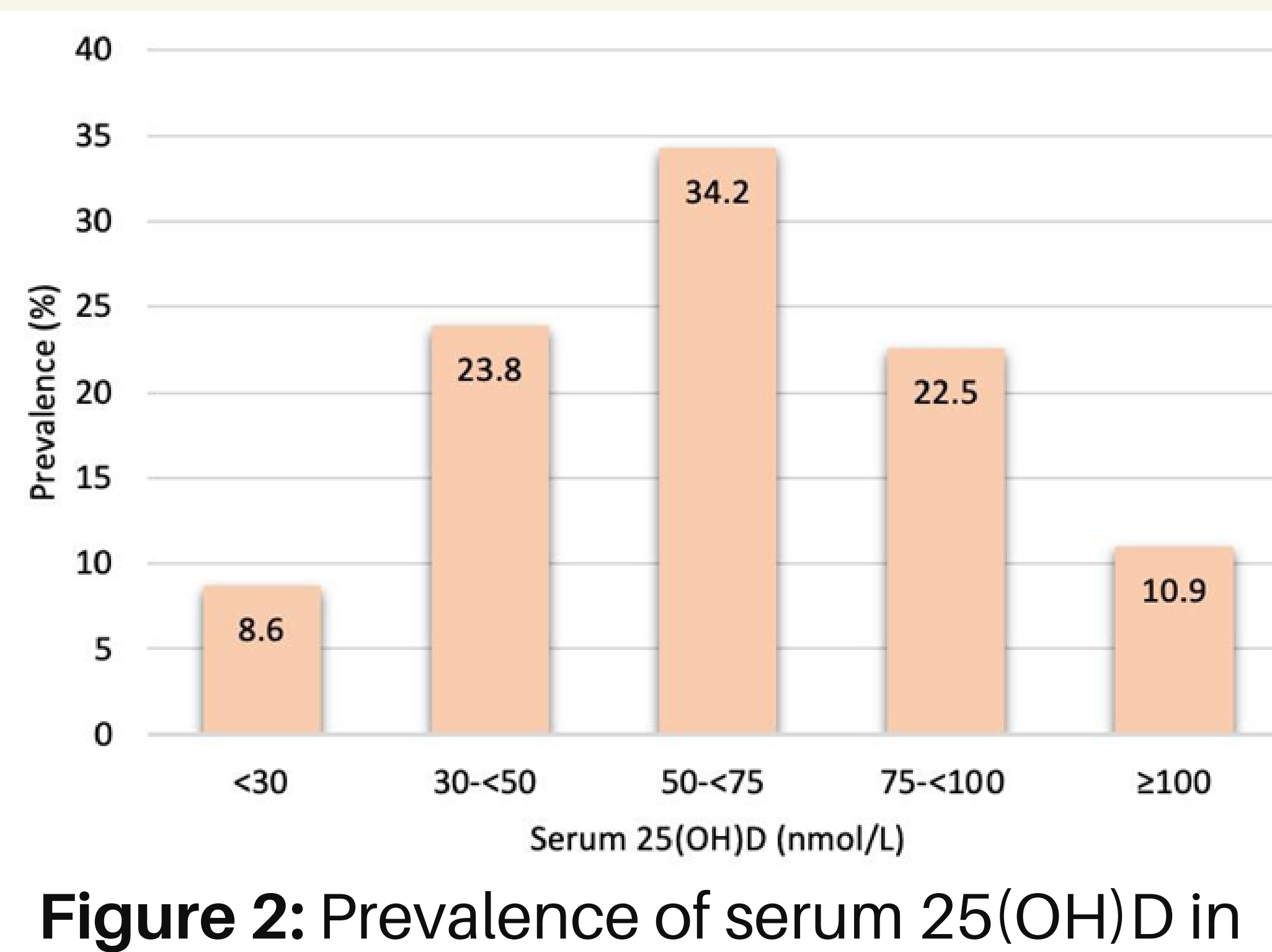

Figure 2: Prevalence of serum 25(OH)D in post-menopausal women

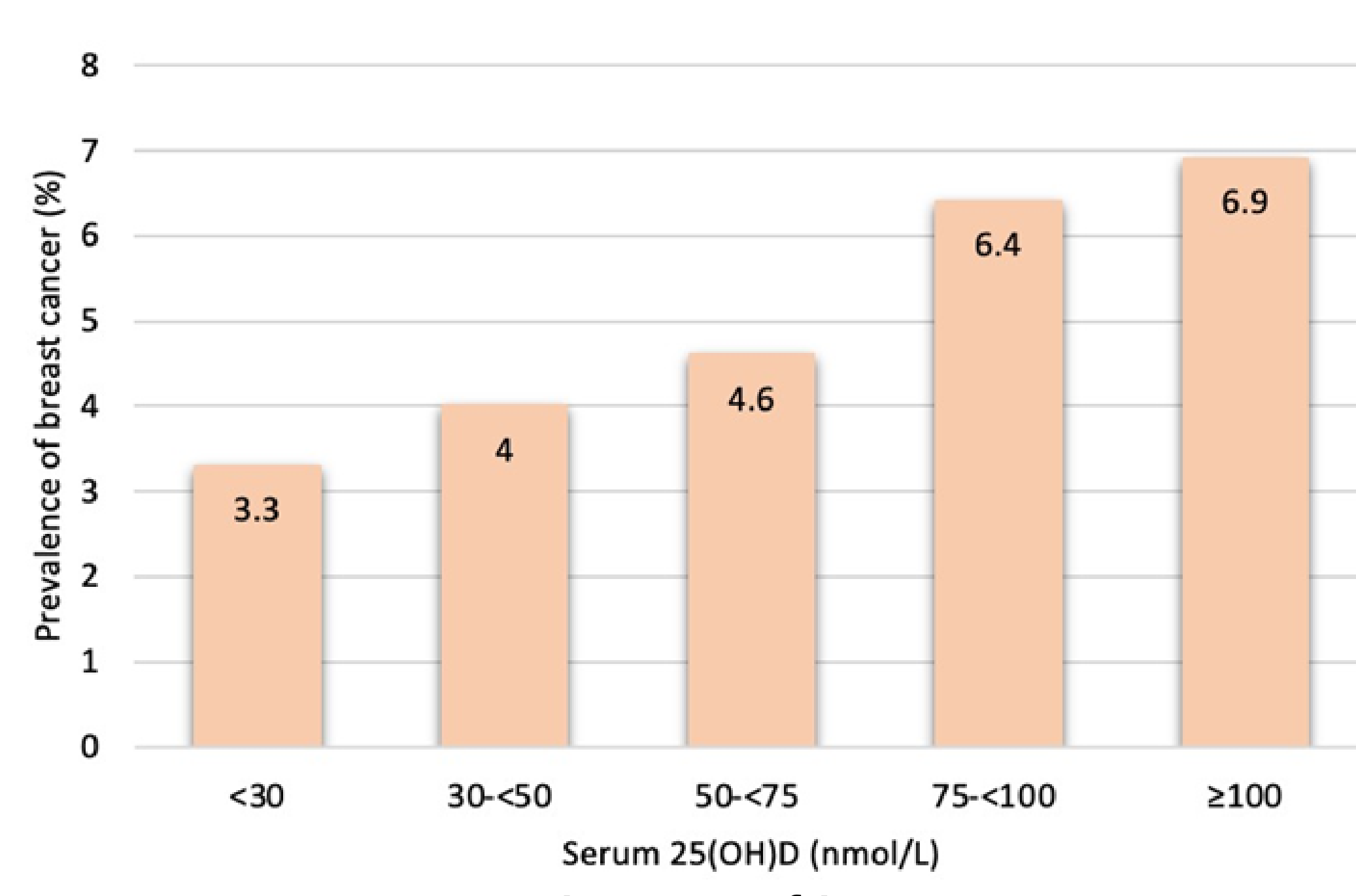

Figure 3: Prevalence of breast cancer in post-menopausal women

\section{Conclusion}

- A direct association was observed between serum 25(OH)D and breast cancer up to 100 $\mathrm{nmol} / \mathrm{L}$.

- It appears that more than $100 \mathrm{nmol} / \mathrm{L}$ may be protective against breast cancer in all postmenopausal women and specifically in NHW.

- Controlled trials are needed to study the association between serum 25(OH)D and breast cancer risk and to elucidate the mechanism of vitamin $D$ in cancer pathogenesis in post-menopausal women.

\begin{tabular}{|c|c|c|c|c|c|c|}
\hline \multicolumn{7}{|c|}{ Serum $25(\mathrm{OH}) \mathrm{D}$ concentrations } \\
\hline & $\begin{array}{c}<30 \\
\mathrm{nmol} / \mathrm{L}^{2} \\
\mathrm{n}=697\end{array}$ & $\begin{array}{c}30<<50 \mathrm{nmol} / \mathrm{L} \\
\mathrm{n}=1929\end{array}$ & $\begin{array}{c}50-<75 \mathrm{nmol} / \mathrm{L} \\
\mathrm{n}=2774\end{array}$ & $\begin{array}{c}75-<100 \mathrm{nmol} / \mathrm{L} \\
\mathrm{n}=1821\end{array}$ & $\begin{array}{c}\geq 100 \mathrm{nmol} / \mathrm{L} \\
\mathrm{n}=879\end{array}$ & $\begin{array}{l}\mathrm{p} \text { for } \\
\text { trend }\end{array}$ \\
\hline Unadjusted & 1 & $\begin{array}{c}1.7 \\
(1.0-3.0)\end{array}$ & $\begin{array}{c}2.0 \\
(1.2-3.4)\end{array}$ & $\begin{array}{c}2.7 \\
(1.6-4.5)\end{array}$ & $\begin{array}{c}2.4 \\
(1.4-4.2)\end{array}$ & $<0.001$ \\
\hline $\begin{array}{c}\text { Race } \\
\text { adjusted }\end{array}$ & 1 & $\begin{array}{c}1.7 \\
(0.9-2.9)\end{array}$ & $\begin{array}{c}1.8 \\
(1.1-3.1)\end{array}$ & $\begin{array}{c}2.4 \\
(1.4-4.0)\end{array}$ & $\begin{array}{c}2.1 \\
(1.2-3.7)\end{array}$ & $0.007^{4}$ \\
\hline $\begin{array}{l}\text { Multivariat } \\
\text { e-adjusted }\end{array}$ & 1 & $\begin{array}{c}1.7 \\
(0.9-3.1)\end{array}$ & $\begin{array}{c}1.8 \\
(1.0-3.3)\end{array}$ & $\begin{array}{c}2.2 \\
(1.2-4.0)\end{array}$ & $\begin{array}{c}1.7 \\
(0.9-3.4)\end{array}$ & $0.032^{6}$ \\
\hline
\end{tabular}

${ }^{1}$ Values are $\mathrm{OR}$ and $95 \% \mathrm{Cl}$. ${ }^{2}$ Referent category. ${ }^{3}$ Significance in logistic regression between serum $25(\mathrm{OH}) \mathrm{D}$ and breast cancer. ${ }^{4} \mathrm{Significance}$ for linear trend. ${ }^{5} \mathrm{Adjusted}$ for age, race, PIR, education, physical activity, season of survey, smoking, alcohol, BMI, supplements intake, and HRT. 'Significance for non-linear trend.

Table 1. Association between 25(OH)D and breast cancer prevalence in post-menopausal women $(n=8100)$

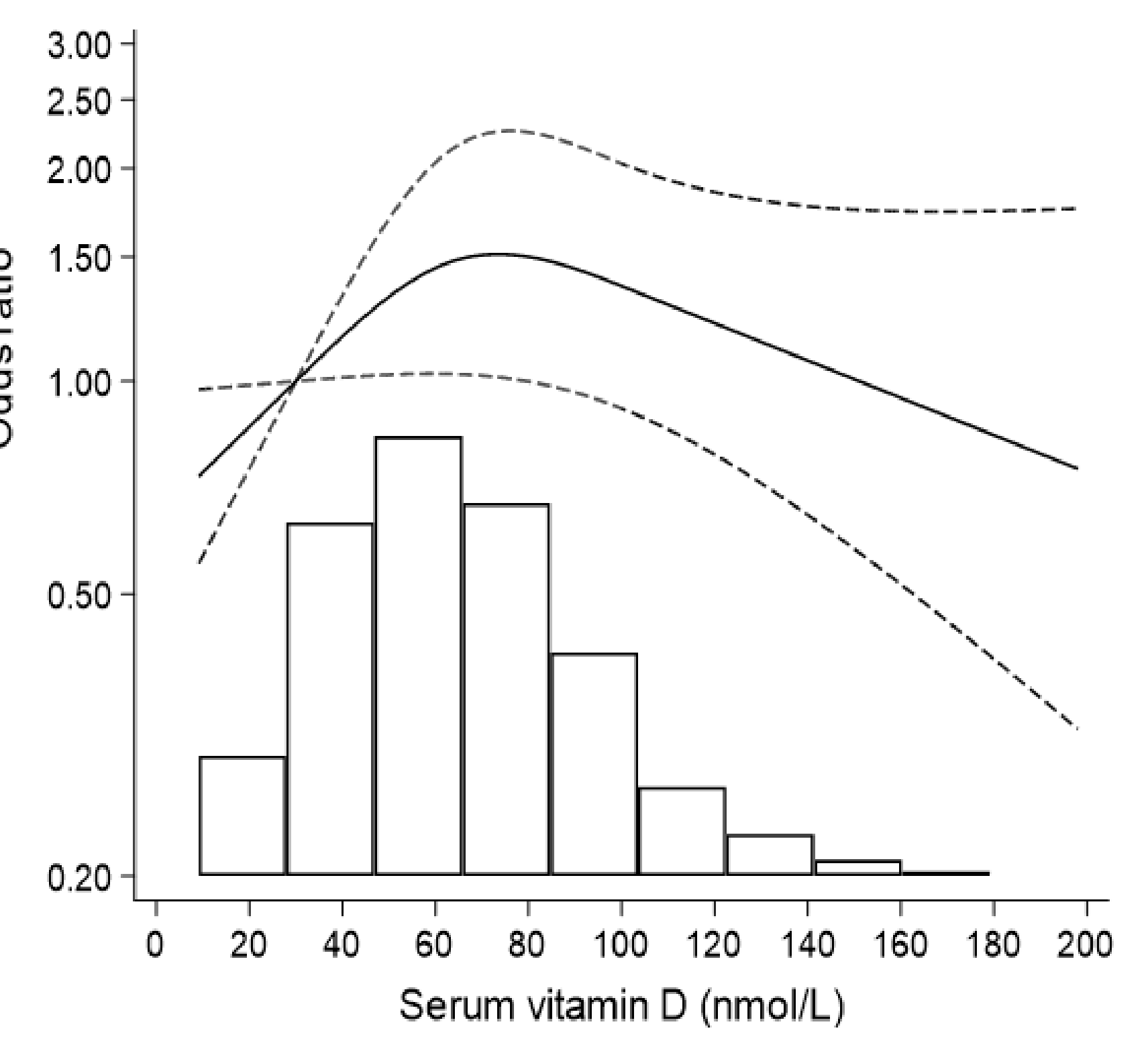

Figure 4: Nonlinear association between serum 25(OH)D and breast cancer prevalence in all post-menopausal women $(n=8100)$ in multivariateadjusted analysis $(P=0.032)$.

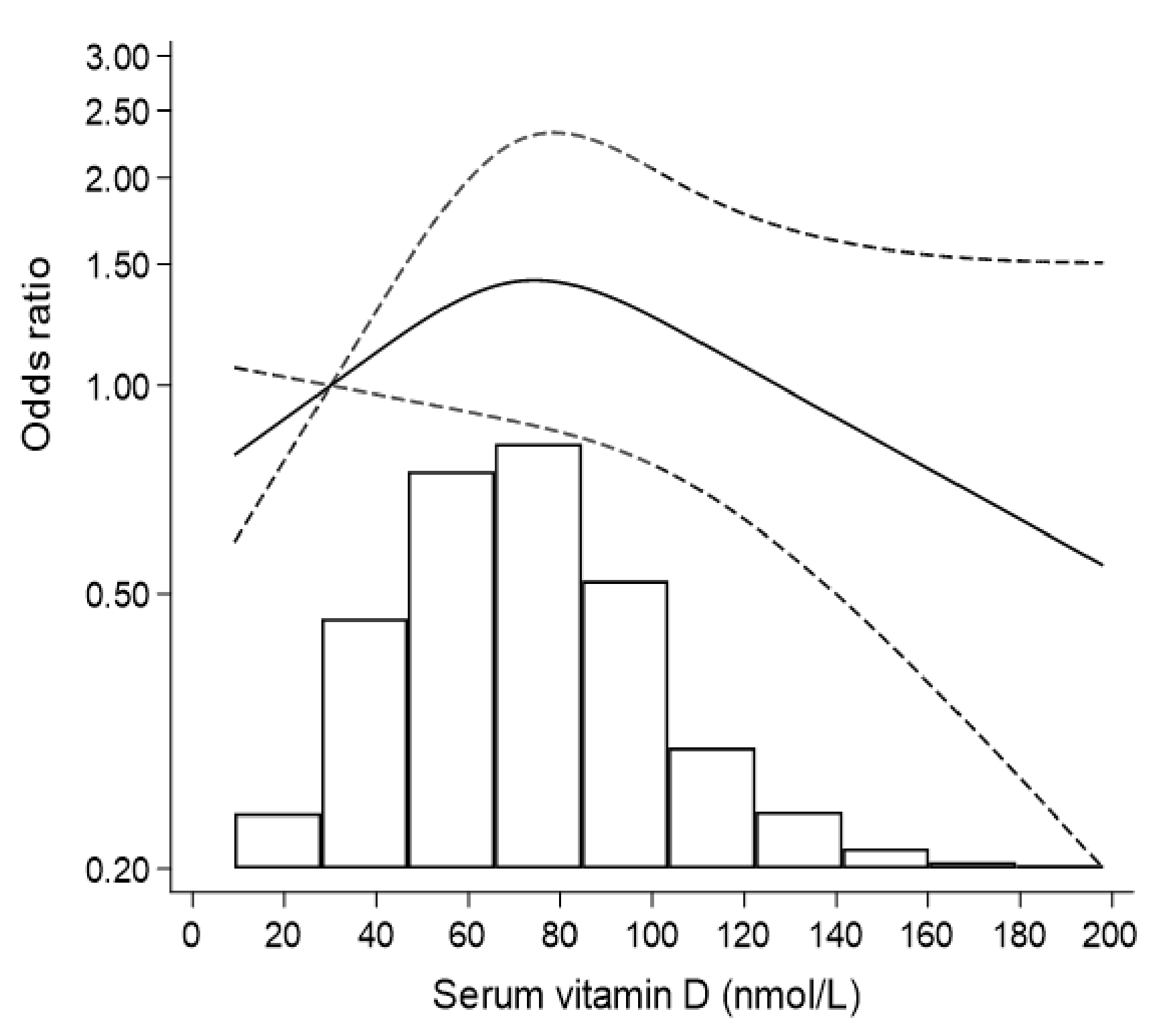

Figure 5: Nonlinear association between 25(OH)D and breast cancer in post-menopausal white women $(n=4298)$ in multivariateadjusted analysis $(P=0.07)$.

\section{Acknowledgement}

The authors would like to extend their deepest gratitude to the support of the Human Nutrition Department at Qatar University. The authors would like to also thank Dr. Zumin for his continuous support and effort and his contribution to the statistical analysis.

Finally, the authors would like to give a special thank you for their families and colleagues for their support throughout the whole process of conducting this study.
- Holick MF, Binkley NC, Bischoff-Ferrari HA, et al. Evaluation, treatment, and prevention of vitamin D deficiency: an Endocrine Society clinical practice guideline. J Clin Endocrinol Metab 2011; 96(7): 1911-30.

- Institute of Medicine Committee to Review Dietary Reference Intakes for Vitamin DaC. The National Academies Collection: Reports funded by National Institutes of Health. In: Ross AC, Taylor CL, Yaktine AL, Del Valle (DC): Natietary Reference Intakes for Calcium and Vitamin D. Washington (DC). National Academies Or

epide effects on breast cancer rates. Maturitas 2010; 67(1): 60-6.

- Song D, Deng Y LuK et al Vitamin Dintake, blod vitamin D levels, and the risk of brest cancer: a dose-response meta-analysis of observation, and studies. Aging (Albany NY) 2019: 11(24): 12708-32.

- Vrieling A, Hein R, Abbas S, Schneeweiss A, Flesch-Janys D, Chang-Claude I. Serum 25-hydroxyvitamin $D$ and postmenopausal breast cancer survival. prospective patient cohort study. Breast Cancer Res 2011; 13(4): R74. Yousef FM, Jacobs ET, Kang PT, et al. Vitamin D status and breast cancer Saudi Arabian women: case-control study. Am J Clin Nutr 2013; 98(1): 105-10. 